\title{
Transfer of Visual Motion Information via Graded Synapses Operates Linearly in the Natural Activity Range
}

\author{
Rafael Kurtz, Anne-Kathrin Warzecha, and Martin Egelhaaf \\ Lehrstuhl für Neurobiologie, Fakultät für Biologie, Universität Bielefeld, Postfach 1001 31, D-33501 Bielefeld, Germany
}

Synaptic transmission between a graded potential neuron and a spiking neuron was investigated in vivo using sensory stimulation instead of artificial excitation of the presynaptic neuron. During visual motion stimulation, individual presynaptic and postsynaptic neurons in the brain of the fly were electrophysiologically recorded together with concentration changes of presynaptic calcium $\left(\Delta\left[\mathrm{Ca}^{2+}\right]_{\text {pre }}\right)$. Preferred-direction motion leads to depolarization of the presynaptic neuron. It also produces pronounced increases in $\left[\mathrm{Ca}^{2+}\right]_{\text {pre }}$ and the postsynaptic spike rate. Motion in the opposite direction was associated with hyperpolarization of the presynaptic cell but only a weak reduc- tion in $\left[\mathrm{Ca}^{2+}\right]_{\text {pre }}$ and the postsynaptic spike rate. Apart from this rectification, the relationships between presynaptic depolarizations, $\Delta\left[\mathrm{Ca}^{2+}\right]_{\text {pre }}$, and postsynaptic spike rates are, on average, linear over the entire range of activity levels that can be elicited by sensory stimulation. Thus, the inevitably limited range in which the gain of overall synaptic signal transfer is constant appears to be adjusted to sensory input strengths.

Key words: calcium cooperativity; fly; graded synapse; insect; lobula plate; motion vision; presynaptic calcium; synaptic gain; synaptic transmission; tangential cell
The small size and inaccessibility of synaptic structures often hampers the analysis of synaptic transmission and its dependency on $\left[\mathrm{Ca}^{2+}\right]_{\text {pre }}$. This problem was partially overcome by combining electrophysiological with optical imaging techniques and by studying either exceptionally large synapses (Augustine et al., 1985; Helmchen et al., 1997) or populations of synapses with similar structure and function (Wu and Saggau, 1994; Regehr and Atluri, 1995). For technical reasons, these studies were performed mainly on slice preparations, using electrical stimulation. However, the results of these studies cannot be easily extrapolated to in vivo conditions, where the range and temporal pattern of presynaptic activity probably differ from artificially induced activity.

Here, we study the transfer of visual motion information at a graded synapse in the fly's brain during sensory stimulation. The electrical activity of identified presynaptic and postsynaptic neurons is recorded, and $\left[\mathrm{Ca}^{2+}\right]_{\text {pre }}$ is imaged in vivo while the cells are activated by visual input. We use stimuli that permit consideration of the whole range of naturally occurring presynaptic activity levels. Both presynaptic and postsynaptic neurons belong to a group of $>30$ individually identifiable neurons, the tangential cells, in the fly's third visual neuropil. Tangential cells respond directionally selective to optic flow as is generated by self motion (for review, see Hausen, 1984; Hausen and Egelhaaf, 1989; Egelhaaf and Borst, 1993). The presynaptic cell belongs to a group of 10 neurons, the so-called vertical system (VS), which is thought to be important for optomotor gaze stabilization. VS

Received Feb. 21, 2001; revised May 14, 2001; accepted June 19, 2001.

This work was supported by the Deutsche Forschungsgemeinschaft (DFG). The authors are grateful to Judith Eikermann for technical assistance, to Hinrich Schulenburg for linguistic support, and to Norbert Böddeker, Katja Karmeier, and Roland Kern for helpful discussions of this work. We also thank two anonymous reviewers for their helpful comments on an earlier version of this manuscript.

Correspondence should be addressed to Rafael Kurtz, Lehrstuhl für Neurobiologie, Fakultät für Biologie, Universität Bielefeld, Postfach 1001 31, D-33501 Bielefeld, Germany. E-mail: rafael.kurtz@biologie.uni-bielefeld.de.

Copyright (C) 2001 Society for Neuroscience $0270-6474 / 01 / 216957-10 \$ 15.00 / 0$ cells gather input from numerous retinotopically organized elements, each sensitive to local motion. As a consequence, VS neurons possess large receptive fields, in which they are sensitive to motion in a predominantly vertical direction (Hengstenberg et al., 1982; Krapp et al., 1998). Intracellular recordings from VS cell axons close to the output region show graded membrane potential changes, superimposed by spike-like depolarizations of variable amplitude. The output sites of VS neurons could be identified by the presence of presynaptic specializations (Hausen et al., 1980). The postsynaptic V1 neuron relays motion signals provided by VS cells to the contralateral visual system. Action potentials of V1 were recorded extracellularly.

The highly nonlinear nature of synaptic processes limits the range in which synaptic gain is constant. We analyze $\left[\mathrm{Ca}^{2+}\right]_{\text {pre }}$ because $\mathrm{Ca}^{2+}$ was shown to render synaptic transmission nonlinear, for instance by binding in a cooperative manner to the sensor that triggers transmitter release (Dodge and Rahamimoff, 1967; Smith et al., 1985). However, the $\mathrm{Ca}^{2+}$ dependence of transmitter release may be different for synaptic terminals that transform gradually changing presynaptic voltages into transmitter release instead of signaling action potentials. The dependency of synaptic transmission on $\mathrm{Ca}^{2+}$ has been studied only rarely at graded synapses, although neuronal information is frequently signaled by graded membrane potential changes, e.g., in the insect peripheral visual system and in the vertebrate retina and olfactory bulb (for review, see Juusola et al., 1996; Mori et al., 1999; von Gersdorff, 2001). Therefore, insights into the mode of action of graded synapses should help to provide a better understanding of neuronal information transmission.

\section{MATERIALS AND METHODS}

Double recordings were performed in vivo from one of the visual motion sensitive VS neurons and the postsynaptic V1 neuron in female blowflies (Calliphora erythrocephala), aged 1-3 d. The electrophysiological analysis was combined with fluorescence imaging of $\Delta\left[\mathrm{Ca}^{2+}\right]_{\text {pre }}$ in the VS cell.

VS neurons show graded depolarization and hyperpolarization in response to ipsilateral downward and upward motion, respectively 
(Hengstenberg, 1982; Hengstenberg et al., 1982; Krapp et al., 1998). VS cells could be identified by the location of their receptive fields and by visualization of their anatomy using fluorescent dye staining. The V1 neuron was recorded in the ventral region of the lobula plate, which is the posterior part of the third visual neuropil, contralateral to the recorded VS cell. This region includes V1's main telodendritic arborization. V1 was identified by its excitatory response to downward motion in the frontal contralateral visual field (Hausen, 1984; Hausen and Egelhaaf, 1989).

Animal preparation followed Dürr and Egelhaaf (1999), with the addition that both hemispheres of the brain were made accessible by cutting small holes into the head capsule. Moreover, the upper part of the thorax was removed such that a $40 \times$ water immersion objective could be positioned sufficiently close to the axon terminal of the VS cell. The compound eye contralateral to the recorded VS neuron was covered with black paint to ensure that the neurons were excited exclusively by ipsilateral retinotopic input to the VS cells. The experiments were performed at room temperature $\left(18-23^{\circ} \mathrm{C}\right)$.

Electrophysiology. Experiments were begun by recording V1 extracellularly. We used standard recording equipment and glass electrodes made from borosilicate glass (GC150TF-15; Clark Electromedical, Edenbridge, UK) on a vertical puller (Getra, Munich, Germany). Electrode resistances were $4-8 \mathrm{M} \Omega$ when filled with $1 \mathrm{M} \mathrm{KCl}$. Ringer's solution containing (in mM: $\mathrm{NaCl} 128.3, \mathrm{KCl} 5.4, \mathrm{CaCl}_{2} 1.9, \mathrm{NaHCO}_{3} 4.8$, $\mathrm{Na}_{2} \mathrm{HPO}_{4} 3.3, \mathrm{KH}_{2} \mathrm{PO}_{4} 3.4$, glucose 13.9, $\mathrm{pH} 7.0$ (all chemicals were from Merck, Darmstadt, Germany), was used to prevent desiccation of the brain and to fill a wide-tip glass pipette that served as an indifferent electrode. Action potentials were transformed into pulses of fixed height and duration. They were sampled at a rate of $1 \mathrm{kHz}$ by an analog-todigital (AD) converter (DT2801A; Data Translation, Marlboro, MA).

Once a stable V1 recording was established, a VS neuron was recorded intracellularly with electrodes made from borosilicate glass (GC100TF10, Clark Electromedical) on a Brown-Flaming puller (P97; Sutter Instruments, San Rafael, CA). Electrode resistances were 20-40 M $\Omega$ when filled with $1 \mathrm{M} \mathrm{KCl}$. The tip of the electrode was filled either with a solution containing the calcium-sensitive dye (see next paragraph) or with a saturated solution of Lucifer yellow (Sigma, Deisenhofen, Germany) in $1 \mathrm{M} \mathrm{LiCl}$. The shaft of the electrode was filled with either $1 \mathrm{M}$ $\mathrm{KCl}$ or $1 \mathrm{M} \mathrm{LiCl}$, respectively. Membrane potential changes $(\Delta E)$ were recorded in bridged mode (Axoclamp 2A; Axon Instruments, Foster City, CA) and $\mathrm{AD}$ converted at a sampling rate of $1 \mathrm{kHz}$ with an amplitude resolution of $0.0244 \mathrm{mV}$ (DT2801A, Data Translation). Part of the recordings were performed during iontophoretic injection of the fluorescent dye by a weak tonic hyperpolarizing current $(<1 \mathrm{nA})$. The electrical responses did not differ significantly between cells hyperpolarized with this method and cells recorded without current injection.

Imaging of $\mathrm{Ca}^{2+}$ concentration changes in VS neurons. $\mathrm{A} \mathrm{Ca}^{2+}$-sensitive dye, either fura-2 $\left(K_{\mathrm{d}}=224 \mathrm{~nm}\right.$; all of the data shown, except Fig. $\left.1 A\right)$ or bis-fura-2 $\left[K_{\mathrm{d}}=370 \mathrm{nM}\right.$; data shown in Fig. $1 A$; dissociation constants according to Takahashi et al. (1999)], was injected into single VS neurons by a hyperpolarizing current of $<1 \mathrm{nA}$. Electrode tips contained (in $\mathrm{mm}$ ): KCl 33.3 (Sigma), KOH 1.7 (Merck), fura-2 (or bis-fura-2) pentapotassium salt 20.0 (Molecular Probes, Eugene, OR), HEPES 33.3 (Sigma), $\mathrm{pH}$ 7.3. Relative changes of intracellular ionic free- $\mathrm{Ca}^{2+}$ concentration $\left(\Delta\left[\mathrm{Ca}^{2+}\right]\right)$ were determined during or immediately after electrophysiological recording using single wavelength measurements according to Vranesic and Knöpfel (1991). Epifluorescence measurements were performed with an upright microscope (Axioskop FS; Zeiss, Oberkochen, Germany). Fluorescence was elicited at $380 \mathrm{~nm}$ (light emitted from a $\mathrm{Hg}$ arc lamp, HBO 100W; Osram, Munich, Germany; bandpass filtered with a bandwidth of $10 \mathrm{~nm}$ ) and measured after passage of a $410 \mathrm{~nm}$ dichroic mirror and a $500-530 \mathrm{~nm}$ bandpass filter. Images were magnified by water immersion objective lenses (Achroplan $10 \times / 0.30$ or $40 \times / 0.75$, Zeiss) and recorded with a charge-coupled device (CCD) camera (PXL; Photometrics, Tucson, AZ), controlled by PMIS software (GKR Computer Consulting, Boulder, $\mathrm{CO}$ ). Acquisition rate was $3 \mathrm{~Hz}$ and spatial resolution $\sim 0.8 \mu \mathrm{m}$ when the $512 \times 512$ pixels of the CCD chip were binned to $128 \times 128$ pixels. Exposition of a $160 \times 160$ pixel sub-area of the CCD chip, binned to $10 \times 10$ pixels, resulted in a temporal resolution of $40 \mathrm{~Hz}$ and a spatial resolution of $\sim 3.2 \mu \mathrm{m}$. Fluorescence changes $(\Delta F / F)$ were determined relative to an image obtained before visual stimulation. Increases in $\left[\mathrm{Ca}^{2+}\right]$ lead to a decrement in fluorescence. For convenience the latter were inverted in the figures when the calcium signals were compared with the electrical signals of a cell. Mask areas for $\Delta F / F$ calculation were formed by performing a threshold operation on the raw fluorescence image and choosing appropriate sections (see Fig. 1). When $\Delta F / F$ was to be compared in regions with different staining intensity, background fluorescence was determined for each image in a region surrounding the dendrite and subtracted from the raw fluorescence images. Because background subtraction adds considerable noise to the $\Delta F / F$ calculation, it was not performed in comparisons between stimulus conditions only. Only relative $\Delta\left[\mathrm{Ca}^{2+}\right]$ values can be obtained by the single wavelength method. By ratiometric measurements with fura-2, the absolute value of resting $\left[\mathrm{Ca}^{2+}\right]$ in VS neurons was determined to be within 20-60 nM in vivo (Egelhaaf and Borst, 1995) and 50-180 nM in an in vitro preparation of the fly brain (Oertner et al., 2001). Short-term sensory or electrical stimulation, and also application of the cholinergic agonist carbachol, produced a two- to threefold increase in $\left[\mathrm{Ca}^{2+}\right]$ (Oertner et al., 2001).

Visual stimuli. Stimuli consisted of moving bar patterns. These were generated by a board with 1440 green $2.5 \times 4.8 \mathrm{~mm}$-sized LEDs, arranged in 48 rows and 30 columns (designed and produced in our electronic workshop). Switching on and off neighboring LED rows with an appropriate time shift resulted in apparent vertical motion that is visible to the fly. Stimuli covered the frontal visual field ipsilateral to the recorded VS neuron from $\sim 0^{\circ}$ to $50^{\circ}$ along the azimuth with respect to the midline and $\pm 30^{\circ}$ relative to the horizontal plane of the fly. During each stimulus sweep, a square-wave grating with a spatial wavelength of $32^{\circ}$ was stationary for $2 \mathrm{sec}$ and then moved with a temporal frequency of $4 \mathrm{~Hz}$ for $1 \mathrm{sec}$, followed again by stationary presentation. The pattern was stationary for at least $10 \mathrm{sec}$ before the next sweep started.

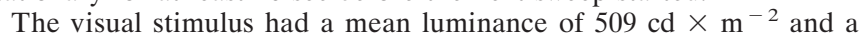
Michelsen contrast of $99.3 \%$. To vary stimulus strength, luminance and contrast were attenuated by gray filters of variable density: filter 1,73 $\mathrm{cd} \times \mathrm{m}^{-2}, 99.2 \%$; filter $2,10 \mathrm{~cd} \times \mathrm{m}^{-2}, 99.1 \%$; filter $3,4 \mathrm{~cd} \times \mathrm{m}^{-2}$, $97.4 \%$; filter $4,0.5 \mathrm{~cd} \times \mathrm{m}^{-2}, 96.2 \%$. The unattenuated stimulus led to maximal responses that can be elicited in VS cells. It had very high contrast and was sufficiently bright, moved at a velocity that is optimal for VS neurons (Hengstenberg, 1982), and covered most of the receptive fields of the recorded cells. Because of gain control, larger stimuli would not lead to significantly stronger responses (Haag et al., 1992).

Data evaluation. In vivo fluorescence measurements in the visual system are complicated by the fact that the excitation light might itself stimulate the photoreceptors. There was indeed some influence of the excitation light on the activity of VS and V1 cells. First, there were weak excitatory on and off reactions during operation of the shutter of the excitation lamp. Second, diminishing the intensity of the visual stimulus with gray filters had a stronger effect on the response amplitude when the fluorescence excitation light was on. Therefore, data were compared only when acquired under exactly the same visual stimulus conditions. This means that even if no simultaneous $\mathrm{Ca}^{2+}$ imaging was performed, electrical recordings were done with epifluorescence excitation through the $40 \times$ water immersion lens to compare electrical with $\mathrm{Ca}^{2+}$ responses.

Relationships between the measured parameters were evaluated by linear regression analysis of double-logarithmic plots of data points. Thus, the slopes of the regression lines represent the exponent of a power-law function of the kind $y=a \times x^{\mathrm{b}}$. Regression lines were fitted to the data points by minimizing the weighted sum of the error squares, with weights given by the variance $\sigma_{\mathrm{i}}^{2}$ of individual data points:

$$
\mathrm{SS}=\sum_{\mathrm{i}=1}^{\mathrm{n}} \frac{\left(y_{\mathrm{i}}-\bar{y}_{\mathrm{i}}\right)^{2}}{\sigma_{\mathrm{i}}^{2}}
$$

In all cases, measured values were obtained for the parameters that were related to each other (i.e., $\Delta E_{\text {pre }}, \Delta\left[\mathrm{Ca}^{2+}\right]_{\text {pre }}$, and postsynaptic spike rate). This makes any a priori assignment of parameter dependency arbitrary. Therefore, we calculated two regression lines, minimizing weighted squared errors once along the ordinate and once along the abscissa. Furthermore, a power-law function was fitted directly to the data points in the positive range of the linear plot by a LevenbergMarquardt algorithm, using the parameter on the abscissa as the independent one.

For data evaluation, routines written in C (Borland, Scotts Valley, CA), Matlab (The Matworks, Natick, MA), or PMIS (GKR Computer Consulting) were used. All data are given as mean \pm SD. 


\section{RESULTS}

The transfer of visual information via graded synapses under in vivo conditions was studied by simultaneous recording of two neurons in the visual motion pathway of the blowfly. The membrane potential of one of the VS neurons was registered by an intracellular electrode. An extracellular recording electrode was placed in the opposite half of the brain to record the action potentials of the V1 neuron, which gets input from VS neurons, thus responding to vertical motion in the contralateral visual field. Once a VS/V1 double recording was established, the synaptic connection between the two cells was verified by current injection. Depolarization of the VS cell led to an increase in V1 spike activity; hyperpolarization led to a decrease. The VS neurons with frontal receptive fields, i.e., VS1 to VS3, are thus shown to be presynaptic to V1. This is also suggested by comparing the receptive fields of both cell types (Krapp et al., 1998, 2001). There is no evidence that V1 receives synaptic input from neurons other than VS.

\section{Visual motion-induced $\mathrm{Ca}^{2+}$ transients in VS cell terminals}

We measured concentration changes of $\mathrm{Ca}^{2+}\left(\Delta\left[\mathrm{Ca}^{2+}\right]\right)$ in single VS neurons with $\mathrm{Ca}^{2+}$-sensitive fluorescent dyes during visual stimulation with a moving bar pattern. At a low magnification, the terminal region can be visualized together with part of the axonal trunk (Fig. $1 A$ ). A series of $128 \times 128$ pixel images, taken at a rate of $3 \mathrm{~Hz}$, shows that downward motion in the ipsilateral visual field leads to $\mathrm{Ca}^{2+}$ accumulation in the VS1 neuron (Fig. 1A). $\Delta\left[\mathrm{Ca}^{2+}\right]$ is more pronounced in the terminal region than in the axonal trunk. This was quantified by comparing the backgroundsubtracted fluorescence changes $(\Delta F / F)$ in two regions of the neuron. $\Delta F / F$ calculated inside a mask area at the terminal was at least 10 times larger than $\Delta F / F$ inside an axonal mask. We obtained similar results for VS2 and VS3. $\Delta\left[\mathrm{Ca}^{2+}\right]$ was also found to be larger in the terminal region than in the main axonal trunk in other tangential cells (Egelhaaf and Borst, 1995).

At a higher magnification the terminal region does not appear to have only a single ending. Instead, the synaptic area shows a branched structure, particularly for VS1. Because the exact location of synaptic connections with $\mathrm{V} 1$ in the terminal region is unknown, we analyzed whether $\Delta\left[\mathrm{Ca}^{2+}\right]$ differs considerably between different branches of the output arborization. The amplitude and time course of background-subtracted $\Delta F / F$ inside various mask areas were compared for visual motion stimuli of variable strengths (Fig. $1 B$ ) (see Materials and Methods for details). There are small differences in the overall size of $\Delta F / F$. However, these should not be overinterpreted because the overall size of $\Delta F / F$ is very sensitive to the exact choice of the background mask. In addition, the decline of $\left[\mathrm{Ca}^{2+}\right]$ after the cessation of stimulus motion is slightly faster in fine tips than in the main branch. Moreover, $\Delta F / F$ amplitudes increase in the fine tips by a nearly constant increment for the five stimulus strengths, whereas in the main branch, the amplitude increment gets smaller for the strongest stimulus. In general, $\Delta\left[\mathrm{Ca}^{2+}\right]$ shows only small differences in different sub-areas of the terminal region, at least when judged by $\mathrm{Ca}^{2+}$ imaging with conventional fluorescence microscopy.

\section{Simultaneous recording of presynaptic $\mathrm{Ca}^{2+}$, presynaptic membrane potential responses, and also postsynaptic spike activity}

$\Delta\left[\mathrm{Ca}^{2+}\right]_{\text {pre }}$ in the terminal region of a VS2 neuron was measured simultaneously with the membrane potential of the cell and the spike activity of the postsynaptic V1 neuron (Fig. 2). As can be seen at high magnification, the terminal region of VS2 is not as branched as that of VS1 (Figs. $1 B, 2 A$ ). To improve the temporal resolution of $\Delta F / F$, we confined imaging to a subregion of the $\mathrm{CCD}$ chip and performed pixel binning, yielding $10 \times 10$ pixel images taken at a rate of $40 \mathrm{~Hz}$. Because there is no means to locate precisely the synaptic contacts of VS neurons with the V1 cell, it is problematic to use $\Delta\left[\mathrm{Ca}^{2+}\right]_{\text {pre }}$ recordings with high temporal but low spatial resolution when the terminal region is extensively branched as is the case for VS1. Therefore, we present only data for VS2 and VS3. Note that the VS1 cells tested did not show obvious differences to $\mathrm{VS} 2 / 3$ as to the characteristics of synaptic transmission to V1.

Visual motion in the preferred direction (PD) induces a graded depolarization in the VS2 neuron and a concomitant increase in spike activity in the postsynaptic $\mathrm{V} 1$ cell (Fig. $2 A) \cdot\left[\mathrm{Ca}^{2+}\right]_{\text {pre }}$ of VS2 rises during visual stimulation. $\left[\mathrm{Ca}^{2+}\right]_{\text {pre }}$ continues to rise with a steady slope during the entire stimulation period of $1 \mathrm{sec}$, whereas both the membrane potential change of VS2 $\left(\Delta E_{\text {pre }}\right)$ and the postsynaptic spike rate of V1 reach a steady-state level soon after stimulus onset. After cessation of stimulus motion, both $\Delta E_{\text {pre }}$ and the postsynaptic spike rate decay rapidly to baseline levels. In contrast, the decline of $\left[\mathrm{Ca}^{2+}\right]_{\text {pre }}$ is even slower than its rise. A reduction in the strength of the visual stimulus results in weaker $\Delta E_{\text {pre }}$ and $\Delta\left[\mathrm{Ca}^{2+}\right]_{\text {pre }}$ responses and lower postsynaptic spike activity. Null direction (ND) motion leads to hyperpolarization of the VS2 cell. A slight decline of $\left[\mathrm{Ca}^{2+}\right]_{\text {pre }}$ and a depression of the postsynaptic spike activity below the resting level are hardly detectable in single traces but become evident when multiple traces are averaged (Fig. $2 B$ ).

On a finer time scale, V1 spikes appear to be coupled to membrane depolarizations of VS2, not only during stimulation but also when the stimulus pattern is stationary (Fig. 3, insets). In fact, the spike-triggered average of $\Delta E_{\text {pre }}$ indicates that temporally precise coupling of $\mathrm{V} 1$ spikes to $\Delta E_{\text {pre }}$ is more pronounced when the pattern is stationary than during motion stimulation (Fig. 3). This finding might be explained by the fact that during large presynaptic depolarization, tonic transmitter release leads to a continuous activation of the postsynaptic neuron. In this case, the exact timing of spikes seems to depend to a larger extent on the characteristics of the spike generation mechanism (e.g., the refractory period) than on the exact time course of the presynaptic potential. Alternatively, the amplitude of transient depolarizations in VS2 leading to spikes in V1 might be smaller when the membrane potential is on a depolarized level and thus closer to the reversal potential of excitatory currents. Moreover, weak transients might be sufficient to elicit an action potential when the postsynaptic cell is already close to spike threshold. Consequently, the spike-triggered average of $\Delta E_{\text {pre }}$ is expected to show a more prominent peak in response to weak than in response to strong stimulation. This was found in our experiments (Fig. 3).

\section{Characteristics of transfer of visual motion information at the VS2-V1 synapse}

To analyze the dependency of the postsynaptic spike activity on presynaptic voltage, we plotted the spike rate of $\mathrm{V} 1$ against $\Delta E_{\text {pre }}$ of VS2, both averaged during the $1 \mathrm{sec}$ period of visual motion (Fig. $4 A$, left). The responses were determined relative to baseline levels averaged in a $1 \mathrm{sec}$ period before stimulation. Each data point represents a pair of simultaneously measured traces as shown in Figure $2 \mathrm{~A}$. Stimulus strength was varied pseudorandomly during the course of the experiment. Rectification occurs 

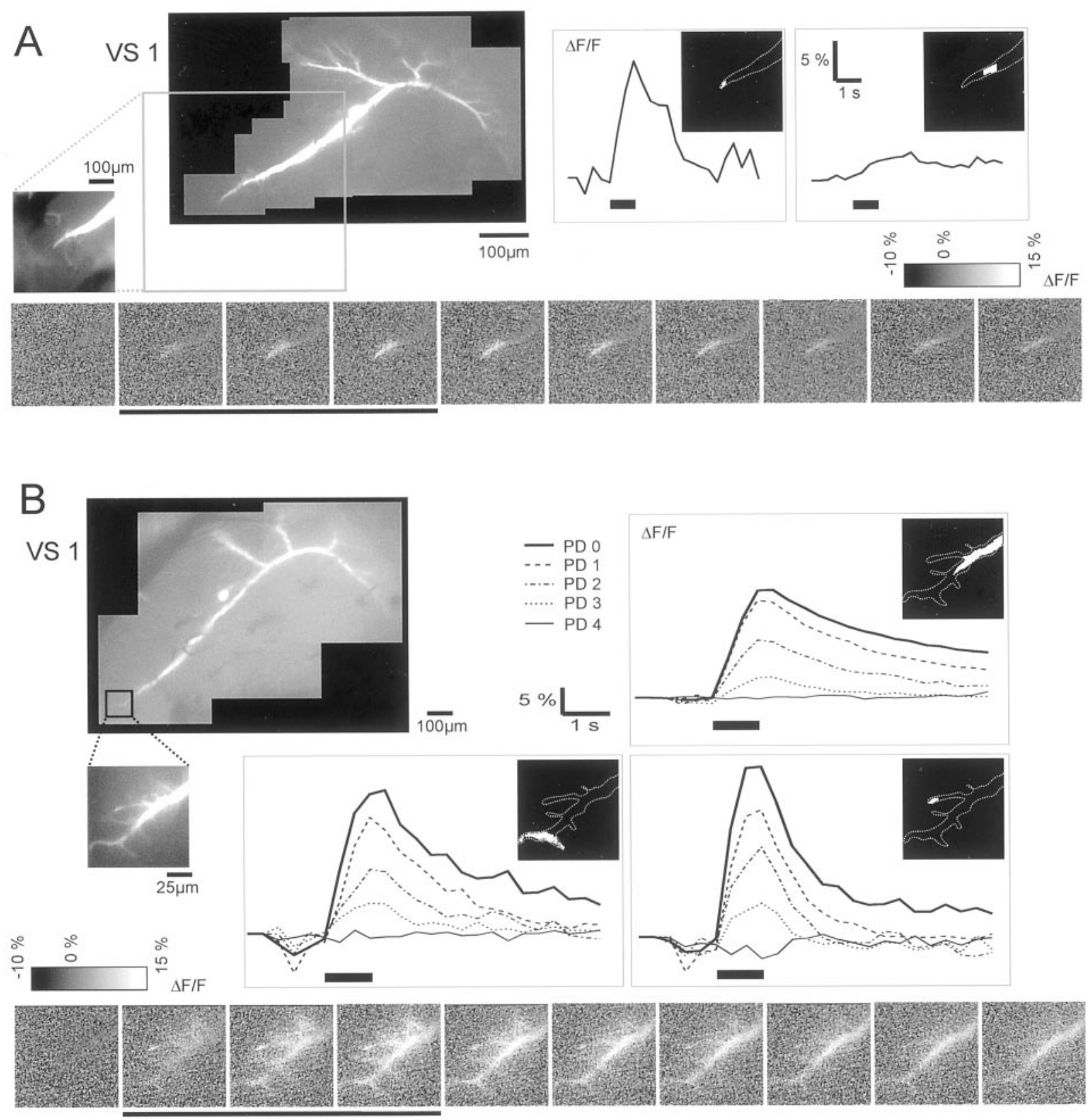

Figure 1. $\mathrm{Ca}^{2+}$ accumulation in the terminal region of VS neurons during in vivo stimulation with visual motion. $A$, VS1 neuron filled with the $\mathrm{Ca}^{2+}$-sensitive fluorescent dye bis-fura-2. A series of images was taken at low magnification (10× microscope objective) with a rate of $3 \mathrm{~Hz}$ during stimulation with motion in the preferred direction $(P D)$. One raw fluorescence image of the series, showing the terminal region and part of the axon, is shown. Its approximate relation to the entire neuron, as visible on the photomontage (top left), is indicated by the box. The time course of $\Delta F / F$ is shown on a series of grayscale images (underlined images taken during motion stimulation). Background-subtracted $\Delta F / F$ time courses are calculated for two different regions, one at the synaptic terminal and the other at the axon. The corresponding mask areas are indicated above each trace (evaluated mask area shown in white; outline of axonal trunk and terminal region indicated by a dotted line). The 1 sec period of stimulus motion is marked by horizontal bars below the traces. Note that $\Delta F / F$ time courses were calculated with background subtraction. For illustrative purposes, the grayscale images show $\Delta F / F$ without background subtraction. $B, \Delta\left[\mathrm{Ca}^{2+}\right]$ in the terminal region of a VS1 neuron, filled with fura-2, was imaged at a higher magnification ( $40 \times$ objective) at a rate of $3 \mathrm{~Hz}$ during presentation of visual motion stimuli of variable strengths ( $P D 0$, unattenuated stimulus; $P D$ 1-PD 4, stimulus attenuated by gray filters of increasing density; see Materials and Methods for details). Presentation of data as in $A$.

in the range of negative $\Delta E_{\text {pre }}$, because VS2 hyperpolarizes during ND motion, whereas the response range of V1 is limited by its low baseline spike activity. During PD motion, the spike rate of V1 increases almost linearly with membrane depolarization, indicating a constant gain over the whole range of stimulation strengths. The dependency of $\Delta\left[\mathrm{Ca}^{2+}\right]_{\text {pre }}$ on $\Delta E_{\text {pre }}$ of VS2 appears to be slightly supralinear for positive $\Delta E_{\text {pre }}$ and is characterized by rectification for negative $\Delta E_{\text {pre }}$ (Fig. $4 A$, middle).
The latter aspect shows that the rectifying transfer characteristic of the VS2-V1 synapse is not necessarily attributable to the low baseline activity of V1. Instead, rectification might already be present on the presynaptic level. In any case, both $\Delta\left[\mathrm{Ca}^{2+}\right]_{\text {pre }}$ and postsynaptic spike rate are not influenced much by ND motion (Fig. $4 A$, right). Furthermore, a slight saturation of the spike rate at high $\Delta\left[\mathrm{Ca}^{2+}\right]_{\text {pre }}$ is visible.

For further analysis, we pooled the data according to the 


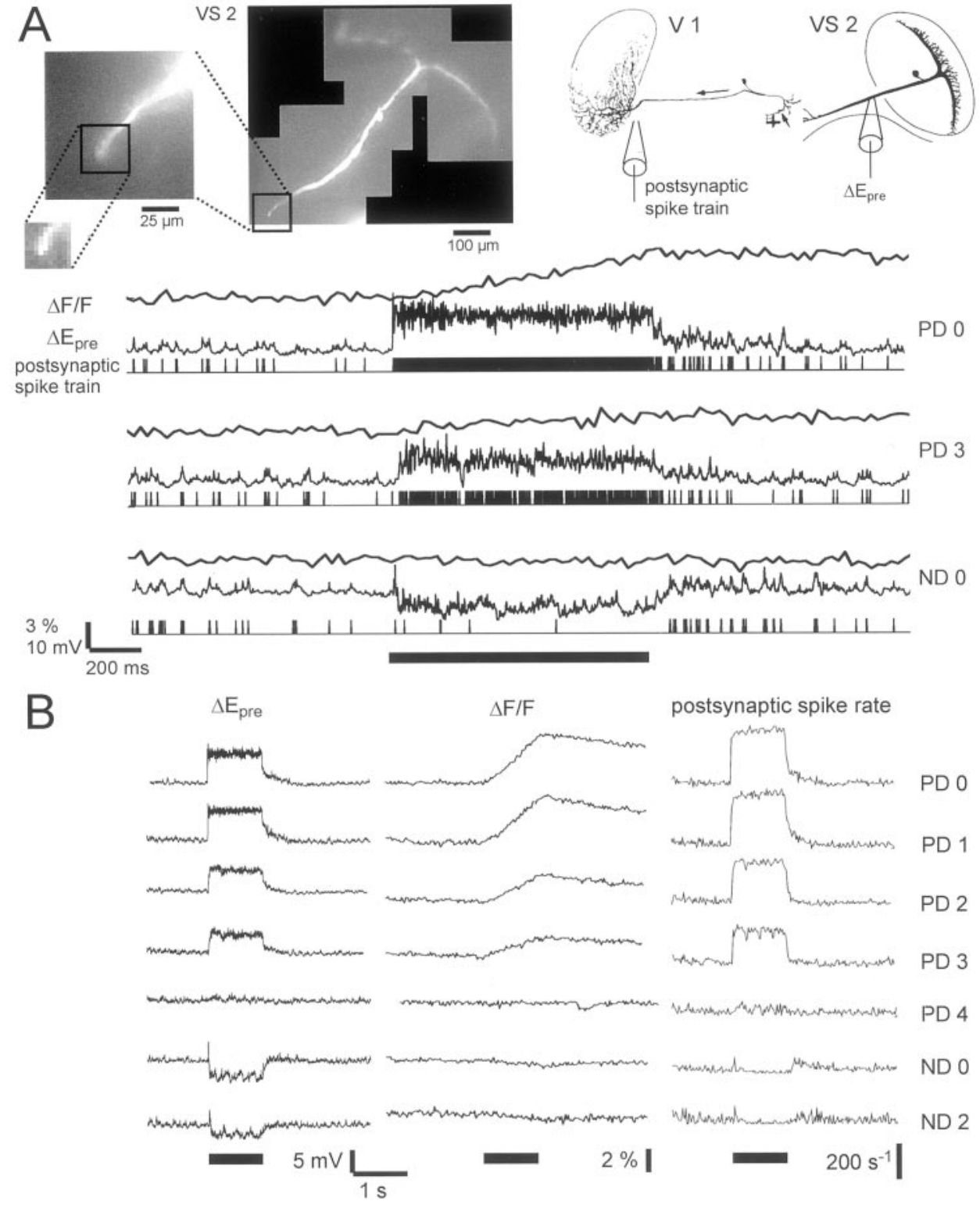

Figure 2. Imaging of the presynaptic $\mathrm{Ca}^{2+}$ concentration combined with double recording of presynaptic membrane potential and postsynaptic spike trains. $A$, Fluorescence imaging of the presynaptic $\mathrm{Ca}^{2+}$ concentration change $\left(\Delta\left[\mathrm{Ca}^{2+}\right]_{\text {pre }}\right)$ in a VS2 neuron during visual motion stimulation was performed at a temporal resolution of $40 \mathrm{~Hz}$ by performing pixel binning and confining image acquisition to a subregion of the full frame (indicated by the box in the raw fluorescence image). Simultaneously, the presynaptic membrane potential response $\left(\Delta E_{\text {pre }}\right)$ and the postsynaptic spike train were recorded. Single traces of $\Delta\left[\mathrm{Ca}^{2+}\right]_{\text {pre }}, \Delta E_{\text {pre }}$, and postsynaptic spike train (action potentials indicated by upright lines) are shown for movement of the unattenuated stimulus in the preferred direction $(P D O)$ and null direction $(N D O)$ and of an attenuated stimulus in the preferred direction (PD 3). Horizontal bar indicates $1 \mathrm{sec}$ period of stimulus motion. Diagram of the circuitry (top right) with reconstructions of V1 and VS2 were taken from Hausen and Egelhaaf (1989) and Krapp et al. (1998), respectively. $B$, Averaged traces of $\Delta E_{\text {pre }}, \Delta\left[\mathrm{Ca}^{2+}\right]_{\text {pre }}$, and postsynaptic spike rate in response to PD and ND motion stimuli of variable strengths for the same neurons as in A. Horizontal bars indicate $1 \mathrm{sec}$ period of stimulus motion. Sample sizes: data on $\Delta E_{\text {pre }}, n=3-9$; data on $\Delta\left[\mathrm{Ca}^{2+}\right]_{\text {pre }}, n=$ 4-13; data on postsynaptic spike rate, $n=$ $5-18 ; n=$ number of traces. In this and in the following figures, the range indicates different sample sizes for the different stimulus strengths. In general, lower sample sizes were gathered for ND stimuli, whereas sample sizes for PD stimuli were in the upper range. stimulus conditions (Fig. 4B). In addition to plotting the data for all stimulus conditions linearly, the positive values were plotted in a log-log diagram (Fig. 4B, insets). The latter diagram permits characterization of the relationships between the measured responses to PD stimuli independent of the rectifying threshold nonlinearity present during ND stimulation. Analogous to previous investigations of synaptic transmission and its $\mathrm{Ca}^{2+}$ dependence, the slope of a linear regression line yields the exponent of a power-law function (Dodge and Rahamimoff, 1967; Smith et al., 1985). Because none of the variables can be regarded to be independent, we calculated two regressions by minimizing summed squares of errors along either the abscissa or the ordinate. Additionally, the results obtained were compared with a power-law function fitted directly to the data points in the positive range of the linear plot. All three approaches yield similar power-law functions for the relationship between the postsynaptic spike rate and $\Delta E_{\text {pre }}$ (Fig. $4 B$, left $)$. In the following, the averaged values of the two power-law exponents of the fits in the log-log plot are given. An almost linear relationship between the postsynaptic spike rate and $\Delta E_{\text {pre }}$ is corroborated by an average exponent of 1.1. The slope in the double-logarithmic plot of $\Delta\left[\mathrm{Ca}^{2+}\right]_{\text {pre }}$ versus $\Delta E_{\text {pre }}$ is 2.1 (Fig. $4 B$, middle), whereas the relationship between the postsynaptic spike rate and $\Delta\left[\mathrm{Ca}^{2+}\right]_{\text {pre }}$ is characterized by an average power-law exponent of 0.4 (Fig. 4B, right). Thus, it may be argued that power-law relationships with exponents above and below 1 in the dependencies of $\Delta\left[\mathrm{Ca}^{2+}\right]_{\text {pre }}$ on $\Delta E_{\text {pre }}$ and of the postsynaptic spike rate on $\Delta\left[\mathrm{Ca}^{2+}\right]_{\text {pre }}$, respectively, compensate each other to result in linear overall transfer of motion information at the VS2-V1 synapse.

\section{Quantitative analysis of synaptic transfer in samples of VS and V1 neurons}

To test whether the above conclusions are a general feature of signal transfer at VS-V1 synapses, a quantitative analysis was performed on the basis of responses of presynaptic VS2 or VS3 neurons, on the one hand, and the postsynaptic V1 cell on the other hand. Because simultaneous recording of $\Delta E_{\text {pre }}$, $\Delta\left[\mathrm{Ca}^{2+}\right]_{\text {pre }}$, and postsynaptic spike rate is extremely difficult, most of the data for the quantitative analysis was gathered not by simultaneous but by sequential recordings, using in each case 

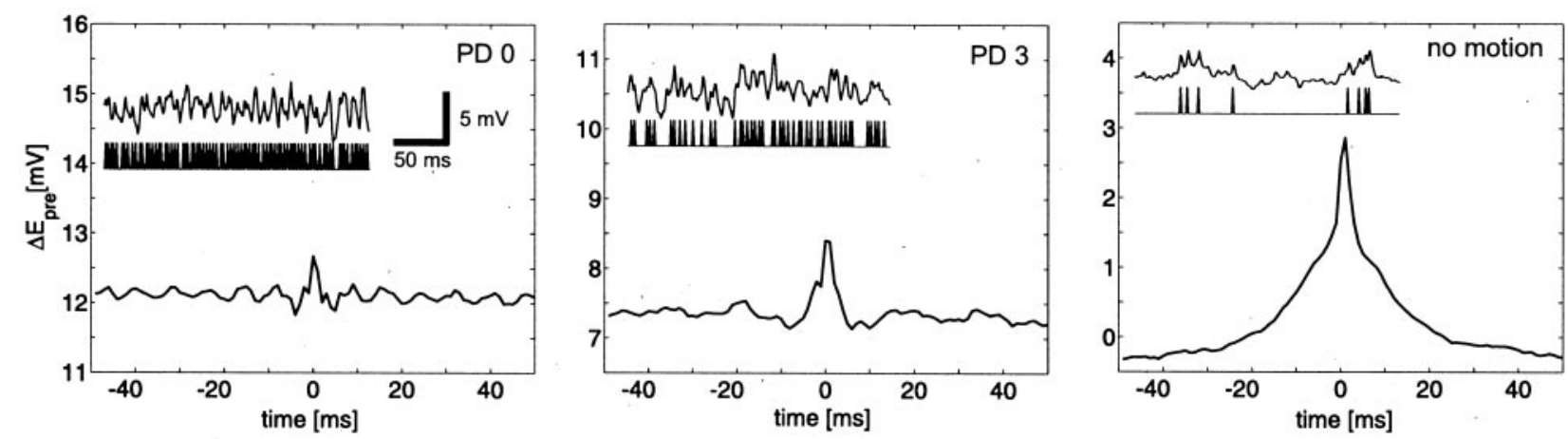

Figure 3. Temporal coupling of postsynaptic spikes to graded presynaptic depolarizations. Spike-triggered averages of $\Delta E_{\text {pre }}$ calculated for periods of pattern motion of the unattenuated stimulus (left, 1610 events), an attenuated stimulus (middle, 877 events), and periods during which the pattern was stationary (right, 773 events). Time 0 corresponds to the occurrence of a postsynaptic spike. A value of 0 on the ordinate indicates the resting potential of the cell. Note the shift in the ordinate range in the subfigures, which is caused by the different depolarization levels of the VS2 neuron. Insets show time courses of $\Delta E_{\text {pre }}$ (top trace) and postsynaptic spike train (bottom trace) on a fine time scale. Data from the same cell pair as in Figure 2.

exactly the same visual stimulus conditions. Data for VS2 and VS3 were pooled, because they did not differ in their physiological characteristics recorded under the stimulus conditions of the present experiments.

The overall relationship between the postsynaptic spike rate and $\Delta E_{\text {pre }}$ across a population of cells is very similar to the sample cell pair described above. Apart from rectification in the range of negative $\Delta E_{\text {pre }}$ values, the transfer gain is constant over the whole operating range, as characterized by an average power-law exponent of 1.0 (Fig. 5, left). When determined for the whole sample of V1 and VS2/3 neurons, the relationships between $\Delta\left[\mathrm{Ca}^{2+}\right]_{\text {pre }}$ and $\Delta E_{\text {pre }}$ (Fig. 5, middle) and between postsynaptic spike rate and $\Delta\left[\mathrm{Ca}^{2+}\right]_{\text {pre }}$ (Fig. 5, right) are also almost linear in the positive range. Average power-law exponents were 0.8 for $\Delta\left[\mathrm{Ca}^{2+}\right]_{\text {pre }}$ versus $\Delta E_{\text {pre }}$ and 1.0 for the postsynaptic spike rate versus $\Delta\left[\mathrm{Ca}^{2+}\right]_{\text {pre }}$. Deviations from linearity in any of the three relationships tested, although present in some of the recordings, were too weak to result in mean power-law exponents considerably different from 1.

\section{Testing for saturation of the $\mathrm{Ca}^{2+}$-sensitive dye}

Our conclusions may depend critically on the choice of time windows for the calculation of response amplitudes. Because the relationships between the measured parameters were basically the same for several time windows $(0-1 \mathrm{sec} ; 0-0.5 \mathrm{sec} ; 0.5-1 \mathrm{sec}$; $0.05-0.25 \mathrm{sec})$, only data for the largest time window $(0-1 \mathrm{sec})$ were presented so far. Nevertheless, a comparison of time windows can help to assess potential saturation of the $\mathrm{Ca}^{2+}$-sensitive dye. If there was saturation, the relationships between electrical and $\mathrm{Ca}^{2+}$ responses should be different when comparing the beginning with the end of the stimulation period. This is to be expected, because considerably higher $\mathrm{Ca}^{2+}$ levels are present at the end. Dye saturation would then lead to a distortion of the relationships. However, for the first and second half of the stimulation period, we found very similar slopes in double-logarithmic plots of $\Delta\left[\mathrm{Ca}^{2+}\right]_{\text {pre }}$ versus $\Delta E_{\mathrm{M}}$ and the postsynaptic spike rate versus $\Delta\left[\mathrm{Ca}^{2+}\right]_{\text {pre }}$ (Fig. 6). This suggests that the $\mathrm{Ca}^{2+}$-sensitive dye is not saturated in our measurements.

\section{Using $\mathrm{Ca}^{2+}$ transients to estimate the presynaptic $\mathrm{Ca}^{2+}$ influx}

The $\mathrm{Ca}^{2+}$ signals recorded in our experiments are probably not equivalent to local $\left[\mathrm{Ca}^{2+}\right]$ at the sensors that regulate transmitter release. Rather, they represent bulk cytosolic $\left[\mathrm{Ca}^{2+}\right]$ in the presynaptic region. It was proposed that $\mathrm{Ca}^{2+}$ influx instead of its overall concentration be considered the parameter that is relevant for transmitter release, unless near-membrane $\left[\mathrm{Ca}^{2+}\right]_{\text {pre }}$ can be measured with very fine spatial resolution (Wu and Saggau, 1994; Sabatini and Regehr, 1996). For transmitter release to be governed by $\mathrm{Ca}^{2+}$ influx, the $\mathrm{Ca}^{2+}$ sensors of the release machinery have to be located in very close proximity to presynaptic $\mathrm{Ca}^{2+}$ channels, and $\mathrm{Ca}^{2+}$ clearance has to be very fast at the release sites. $\mathrm{Ca}^{2+}$ influx can be approximated by taking the first derivative of volume-averaged $\Delta\left[\mathrm{Ca}^{2+}\right]_{\text {pre }}$ over time (Wu and Saggau, 1994; Sabatini and Regehr, 1998). Temporal derivatives of $\Delta\left[\mathrm{Ca}^{2+}\right]_{\text {pre }}, d\left(\Delta\left[\mathrm{Ca}^{2+}\right]_{\text {pre }}\right) / d t$, averaged for VS2/3, are shown in Figure $7 A$. The time courses of $d\left(\Delta\left[\mathrm{Ca}^{2+}\right]_{\text {pre }}\right) / d t$ are similar to that of $\Delta E_{\text {pre }}$, as would be expected for a noninactivating voltageregulated $\mathrm{Ca}^{2+}$ influx. However, $d\left(\Delta\left[\mathrm{Ca}^{2+}\right]_{\text {pre }}\right) / d t$ provides a reasonable estimate of $\mathrm{Ca}^{2+}$ influx only if $\mathrm{Ca}^{2+}$ influx is much faster than $\mathrm{Ca}^{2+}$ efflux. In VS cells, $d\left(\Delta\left[\mathrm{Ca}^{2+}\right]_{\text {pre }}\right) / d t$ probably underestimates $\mathrm{Ca}^{2+}$ influx, because the rise of $\left[\mathrm{Ca}^{2+}\right]_{\text {pre }}$ is at most five times faster than its decline. When the relationships between the electrical responses and the estimated $\mathrm{Ca}^{2+}$ influx are evaluated, such errors should be critical only if the velocity of $\mathrm{Ca}^{2+}$ removal depended on its concentration. In Figure $7 B$, plots of $d\left(\Delta\left[\mathrm{Ca}^{2+}\right]_{\text {pre }}\right) / d t$ versus $\Delta E_{\text {pre }}$ (left $\left.t\right)$ and of the postsynaptic spike rate versus $d\left(\Delta\left[\mathrm{Ca}^{2+}\right]_{\mathrm{pre}}\right) / d t($ right $)$ are shown. The relationships obtained from this analysis are similar to the corresponding ones based on $\Delta\left[\mathrm{Ca}^{2+}\right]_{\text {pre }}$ (Figs. 5, 7B). The average power-law exponents were 0.7 for $d\left(\Delta\left[\mathrm{Ca}^{2+}\right]_{\text {pre }}\right) / d t$ versus $\Delta E_{\text {pre }}$ and 1.4 for postsynaptic spike rate versus $d\left(\Delta\left[\mathrm{Ca}^{2+}\right]_{\text {pre }}\right) / d t$. These values suggest that both the dependency of the $\mathrm{Ca}^{2+}$ influx on $\Delta E_{\text {pre }}$ in the presynapse and the dependency of the postsynaptic spike rate on the presynaptic $\mathrm{Ca}^{2+}$ influx do not deviate much from linearity.

\section{DISCUSSION}

Synaptic information transfer with a constant gain is restricted to a limited operating range. This is because biophysical processes involved in synaptic transmission are inherently nonlinear. First, the activation of presynaptic $\mathrm{Ca}^{2+}$ channels by membrane voltage is often best described by Boltzmann-like relationships (Corey et al., 1984; Borst and Sakmann, 1998). Second, $\left[\mathrm{Ca}^{2+}\right]_{\text {pre }}$ is shaped by diffusion, buffering and the clustering of presynaptic $\mathrm{Ca}^{2+}$ channels (Zucker and Fogelson, 1986; Sala and Hernandez-Cruz, 1990). Third, $\mathrm{Ca}^{2+}$ binds in a cooperative manner to the sensor 

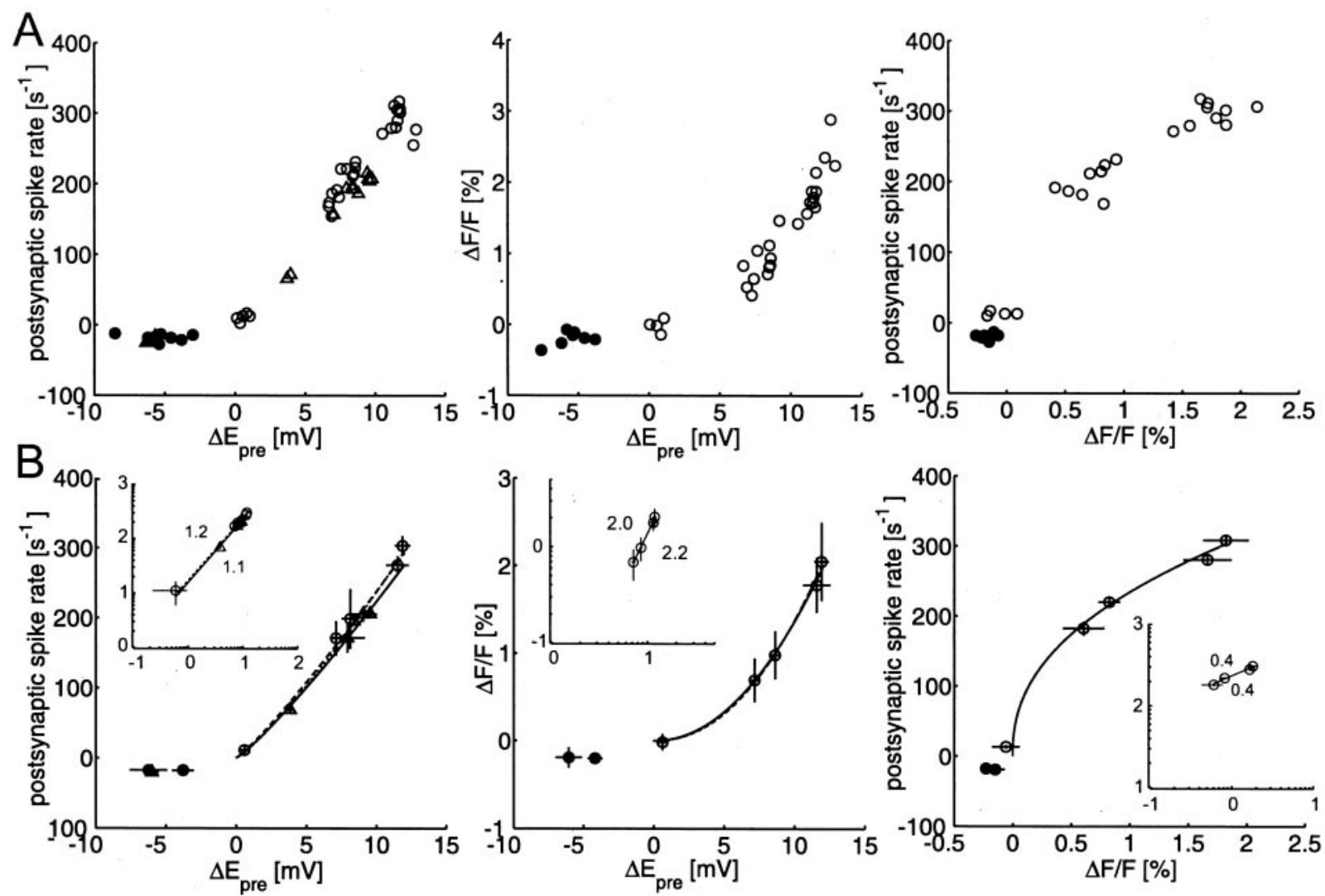

Figure 4. Analysis of synaptic transfer of visual motion information at a single VS2-V1 synapse. $A$, Postsynaptic spike rate plotted against $\Delta E_{\text {pre }}$ for simultaneously measured responses to visual motion of variable strength (left). The recordings were performed either with (circles) or without fluorescence excitation (triangles). Visual motion stimulation was either in the PD (open symbols) or in the ND (filled symbols). Additionally, the relationships between $\Delta\left[\mathrm{Ca}^{2+}\right]_{\text {pre }}$ and $\Delta E_{\text {pre }}$ (middle) and between the postsynaptic spike rate and $\Delta\left[\mathrm{Ca}^{2+}\right]_{\text {pre }}$ (right) are shown for simultaneously recorded traces. All values are time averages of individual responses during the $1 \mathrm{sec}$ period of motion stimulation relative to baseline levels in a $1 \mathrm{sec}$ period before motion onset. $B$, The data shown in $A$ are averaged according to stimulation strength. Positive values are plotted on a double-logarithmic scale (insets). Axis tick labels denote exponents to a base of 10 . Two regression lines were calculated by minimizing weighted squared errors once along the ordinate (dashed lines) and once along the abscissa (solid lines). Their slopes are given above and below the respective lines. The corresponding power-law functions are also shown in the linear plots, together with a power-law function fitted by a Levenberg-Marquardt algorithm to the data points in the positive range of the linear plot, using the parameter on the abscissa as the independent one (dotted lines; the power-law exponents, $b$, are postsynaptic spike rate versus $\Delta E_{\text {pre }}, b=1.2 ; \Delta\left[\mathrm{Ca}^{2+}\right]_{\text {pre }}$ versus $\Delta E_{\text {pre }}, b=2.1$, postsynaptic spike rate versus $\left.\Delta\left[\mathrm{Ca}^{2+}\right]_{\text {pre }}, b=0.4\right)$. Note that all three fitted functions largely superimpose for the given data. All error bars denote SD. Data are obtained from the same pair of cells as those shown in Figures 2 and 3. Sample sizes: data on $\Delta E_{\text {pre }}, n=3-8$; data on $\Delta\left[\mathrm{Ca}^{2+}\right]_{\text {pre }}, n=2-7$ traces; data on postsynaptic spike rate, $n=3-6 ; n=$ number of traces per data point.

that triggers transmitter release. As a consequence, the postsynaptic response was found to be proportional to the third or fourth power of $\left[\mathrm{Ca}^{2+}\right]_{\text {pre }}$ in several synapses (Dodge and Rahamimoff, 1967; Smith et al., 1985; Heidelberger et al., 1994; Wu and Saggau, 1994; Bollmann et al., 2000; Schneggenburger and Neher, 2000) (but see also Peng and Zucker, 1993). Despite these nonlinearities, our results indicate that a graded synapse in the fly visual system transforms presynaptic depolarizations almost linearly into a postsynaptic spike rate when operating in the natural range of excitation levels as elicited in vivo by visual stimulation. Moreover, the relationship between presynaptic potential and $\Delta\left[\mathrm{Ca}^{2+}\right]_{\text {pre }}$ and between $\Delta\left[\mathrm{Ca}^{2+}\right]_{\text {pre }}$ and the postsynaptic spike rate was found to be approximately linear at least during preferred direction motion. However, a rectification nonlinearity was apparent for motion in the null direction of the cell. This rectification might be attributable to $\mathrm{Ca}^{2+}$, because $\Delta E_{\text {pre }}$ hyperpolarizes during null direction motion, whereas $\Delta\left[\mathrm{Ca}^{2+}\right]_{\text {pre }}$ decreases only slightly. It is not clear whether this nonlinearity also applies to near-membrane $\mathrm{Ca}^{2+}$. If efflux mechanisms are slow, hyperpolarization might decrease bulk $\left[\mathrm{Ca}^{2+}\right]$ only weakly and with some delay, whereas there might be a pronounced instantaneous drop in $\mathrm{Ca}^{2+}$ influx close to the presynaptic membrane.

\section{Saturation and exogenous buffering in measurements with a high-affinity $\mathrm{Ca}^{2+}$ indicator}

Fura-2, the fluorescent dye used in most of our experiments, has a high affinity for $\mathrm{Ca}^{2+}$. This feature has two consequences that might be critical for our conclusions. (1) At low dye concentrations, saturation arises even at relatively low $\left[\mathrm{Ca}^{2+}\right]$ (Regehr and Atluri, 1995; Sinha et al., 1997). (2) Particularly if dye concentrations are high, the dye acts as a $\mathrm{Ca}^{2+}$ buffer, slowing the declining phase of $\mathrm{Ca}^{2+}$ transients (Sala and Hernandez-Cruz, 1990; Helmchen et al., 1996; Sinha et al., 1997). In our experiments, the dye concentration could be controlled only roughly by the duration of iontophoretic injection. Nevertheless, we conclude that dye concentration was not in a critical range. First, the time courses of $\Delta\left[\mathrm{Ca}^{2+}\right]$ in fly tangential cells are relatively slow even when measured with low-affinity dyes (Haag and Borst, 2000). Second, peak $\Delta\left[\mathrm{Ca}^{2+}\right]_{\text {pre }}$ values at graded VS-V1 synapses seem to be 

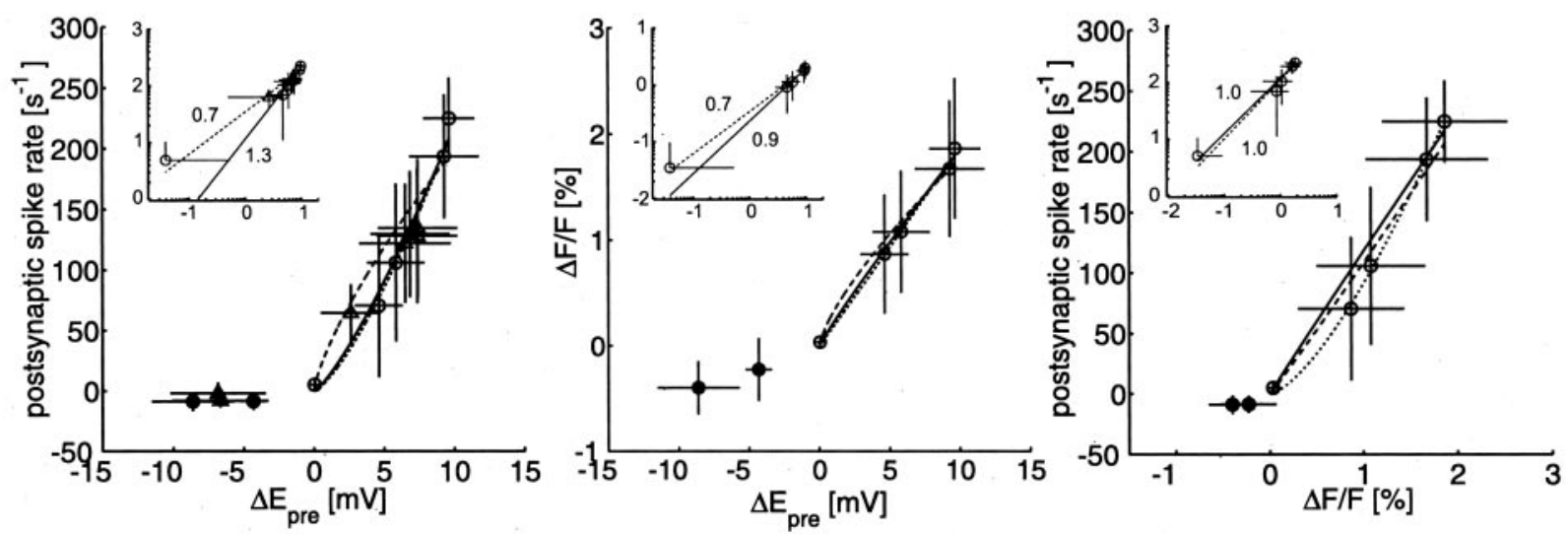

Figure 5. Linearity of synaptic transfer of visual motion information at VS-V1 synapses. The relationship between postsynaptic spike rate and $\Delta E_{\text {pre }}$ (left) is plotted for the entire sample of analyzed VS2/3 and V1 neurons. Recordings were performed with (circles) and without fluorescence excitation (triangles). Filled symbols denote ND; open symbols denote PD stimulation. Additionally, the relationships between $\Delta\left[\mathrm{Ca}^{2+}\right]_{\mathrm{pre}}$ and $\Delta E_{\text {pre }}($ middle) and between the postsynaptic spike rate and $\Delta\left[\mathrm{Ca}^{2+}\right]_{\text {pre }}$ (right) are plotted for the entire sample of analyzed neurons. For all data sets, averages for each stimulation strength were first calculated for individual neurons, then across the sample of neurons. Regression analysis was performed as in Figure 4. The power-law exponents of the fits in the linear plots (dotted lines) are postsynaptic spike rate versus $\Delta E_{\text {pre }}, b=1.4 ; \Delta\left[\mathrm{Ca}^{2+}\right]_{\text {pre }}$ versus $\Delta E_{\text {pre }}, b=1.0$; postsynaptic spike rate versus $\Delta\left[\mathrm{Ca}^{2+}\right]_{\text {pre }}, b=1.4$. Sample sizes: data on $\Delta E_{\text {pre }}, N=4-15, n=6-41$; data on $\Delta\left[\mathrm{Ca}^{2+}\right]_{\text {pre }}, N=4-7, n=16-53$; data on postsynaptic spike rate, $N=7-11, n=37-196 ; N=$ number of cells and $n=$ number of traces per data point.

comparatively low, rendering dye saturation less critical. For example, single action potentials lead to $\Delta F / F$ of $50-150 \%$ in presynaptic varicosities of rat neocortical neurons (Cox et al., 2000 ), whereas in our work, background-subtracted $\Delta F / F$ never exceeded $30 \%$. Third, We also performed experiments with the medium affinity dye bis-fura-2 (three VS1, two VS2/3 cells; data not shown). Neither $\Delta\left[\mathrm{Ca}^{2+}\right]_{\text {pre }}$ time courses nor the relationships between $\Delta\left[\mathrm{Ca}^{2+}\right]_{\text {pre }}$ and electrical responses were obviously different from those measured with fura-2. Finally, power-law exponents estimated for the relationships between $\Delta\left[\mathrm{Ca}^{2+}\right]_{\text {pre }}$ and electrical responses at the beginning of the stimulation period did not differ from those estimated for the end (Fig. 6). Such a difference would be expected as a consequence of dye saturation.

\section{$\mathrm{Ca}^{2+}$ dependence of spike-mediated and graded synaptic transmission}

The linear relationship between postsynaptic spike rate and $\Delta\left[\mathrm{Ca}^{2+}\right]_{\text {pre }}$ found in the present study appears to contrast with $\mathrm{Ca}^{2+}$ cooperativity at the transmitter release site of spiking neurons (see above). It is therefore important to reiterate that we measured postsynaptic spike rates, whereas in most other studies, postsynaptic potentials or currents were determined. Thus, spike generation in the postsynaptic neuron could have produced a saturation effect, which compensates upstream supralinearities. However, a highly nonlinear relationship between postsynaptic depolarization and resulting spike rate is unlikely, because this relationship was concluded to be linear in another fly tangential cell, the H1 neuron (Warzecha et al., 2000). Evidence supporting $\mathrm{Ca}^{2+}$ cooperativity of transmitter release may still be found if it were possible to measure $\left[\mathrm{Ca}^{2+}\right]_{\text {pre }}$ exactly at the site of synaptic action. We consider this unlikely for two reasons: (1) a linear relationship also exists between the postsynaptic response and the temporal derivative of $\Delta\left[\mathrm{Ca}^{2+}\right]_{\text {pre }}$, which serves as an approximation of $\mathrm{Ca}^{2+}$ influx (Fig. 7), and (2) the analysis of spatial differences of $\left[\mathrm{Ca}^{2+}\right]_{\text {pre }}$ shown in Figure $1 B$ rather supports the possibility that restriction of $\mathrm{Ca}^{2+}$ imaging to finer branches of the terminal region would lead to supralinearity in the dependency of $\Delta\left[\mathrm{Ca}^{2+}\right]_{\text {pre }}$ on $\Delta E_{\text {pre }}$ and saturation in the relationship between postsynaptic spike rate and $\Delta\left[\mathrm{Ca}^{2+}\right]_{\text {pre }}$. This tendency, which is also present in the sample record shown in Figure 4, is inconsistent with $\mathrm{Ca}^{2+}$ cooperativity at the release site.

A difference in the $\mathrm{Ca}^{2+}$ dependence of transmitter release between graded and spike-mediated synaptic transmission appears to be functionally adaptive. During spike-mediated synaptic transmission, a high level of $\mathrm{Ca}^{2+}$ cooperativity could ensure that only action potentials but not minor depolarizations lead to transmitter release, thus increasing the signal-to-noise ratio. In contrast, at a graded synapse, even small $\Delta E_{\text {pre }}$ should be transmitted into transmitter release with a high degree of reliability. Previous data point to fundamental differences in the action of $\mathrm{Ca}^{2+}$ between graded and spike-mediated synaptic transmission. Glutamate release from rod terminals was found to be a linear function of $\mathrm{Ca}^{2+}$ influx through L-type $\mathrm{Ca}^{2+}$ channels (Witkovsky et al., 1997). In recordings of pairs of retinal amacrine cells, a slow phase of transmitter release, linearly dependent on the presynaptic $\mathrm{Ca}^{2+}$ influx, could be discerned from a fast, rapidly
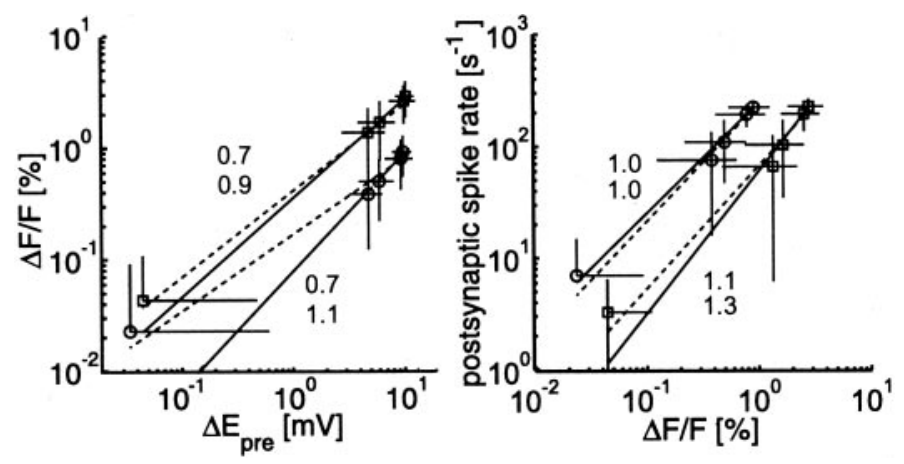

Figure 6. Relationships between $\Delta\left[\mathrm{Ca}^{2+}\right]_{\text {pre }}$ and electrical responses remain constant during the stimulation period. The relationships between $\Delta\left[\mathrm{Ca}^{2+}\right]_{\text {pre }}$ and $\Delta E_{\text {pre }}$ (left $)$ and between the postsynaptic spike rate and $\Delta\left[\mathrm{Ca}^{2+}\right]_{\text {pre }}$ (right) were calculated for time-averaged responses determined during the first half (circles) and second half (squares) of the $1 \mathrm{sec}$ stimulation period. Data set, averaging, and regression analysis are as in Figure 5 (same sample sizes). Similar slopes of the regression lines obtained for both halves of the stimulation period suggest that the $\mathrm{Ca}^{2+}$-sensitive dye is far from saturation in our measurements. 

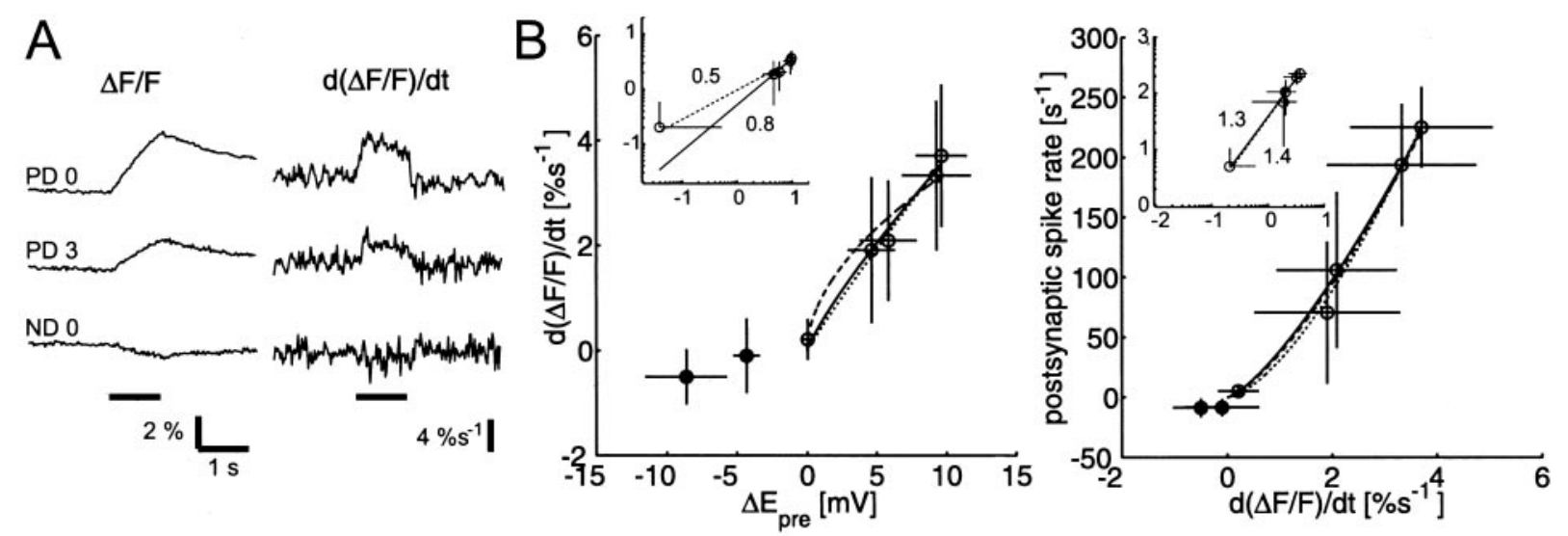

Figure 7. An approximation of $\mathrm{Ca}^{2+}$ influx and its relationship to $\Delta E_{\text {pre }}$ and postsynaptic spike rate. $A$, To estimate $\mathrm{Ca}^{2+}$ influx, $\Delta\left[\mathrm{Ca}^{2+}\right]_{\text {pre }}$ was derived over time. Shown are average time courses of $\Delta\left[\mathrm{Ca}^{2+}\right]_{\text {pre }}$ (left $)$ and $d\left(\Delta\left[\mathrm{Ca}^{2+}\right]_{\text {pre }}\right) / d t$ (right) for VS2/3 $(N=7, n=43-46)$ in response to PD motion stimuli of two different strengths and to an ND motion stimulus of maximal strength. The displayed time courses of $d\left(\Delta\left[\mathrm{Ca}^{2+}\right]_{\text {pre }}\right) / d t$ are smoothed by a running average of $125 \mathrm{msec}$ width. $B$, The relationships between $d\left(\Delta\left[\mathrm{Ca}^{2+}\right]_{\text {pre }}\right) / d t$ and $\Delta E_{\text {pre }}$ (left $)$ and between the postsynaptic spike rate and $d\left(\Delta\left[\mathrm{Ca}^{2+}\right]_{\text {pre }}\right) / d t$ (right) are plotted for the same data set as in Figure 5. Filled symbols denote ND stimulation; open symbols denote PD stimulation. Averaging, sample sizes, and regression analysis are as in Figure 5. The power-law exponents of the fits in the linear plots (dotted lines) are $d\left(\Delta\left[\mathrm{Ca}^{2+}\right]_{\text {pre }}\right) / d t$ versus $\Delta E_{\text {pre }}, b=0.9$; postsynaptic spike rate versus $d\left(\Delta\left[\mathrm{Ca}^{2+}\right]_{\text {pre }}\right) / d t, b=1.5$.

saturating component (Gleason et al., 1994). Biphasic exocytosis is also prominent in goldfish bipolar neurons (von Gersdorff, 2001) and in cochlear inner hair cells (Beutner et al., 2001). A steep dependency on $\mathrm{Ca}^{2+}$ of the fast transient secretory component was concluded from measurements of membrane capacitance jumps during flash photolysis of caged $\mathrm{Ca}^{2+}$ (Heidelberger et al., 1994; Beutner et al., 2001). However, the $\mathrm{Ca}^{2+}$ dependence of the delayed tonic phase of release has not yet been determined. Recently, Ivanov and Calabrese (2000) found that $\Delta\left[\mathrm{Ca}^{2+}\right]_{\text {pre }}$ recorded at the end of fine neuritic branches in leech heart interneurons is roughly linearly related to increases in postsynaptic conductance. Furthermore, there is evidence for differential expression of proteins regulating synaptic vesicle fusion. For example, ribbon synapses of the vertebrate retina express syntaxin 3 rather than syntaxin 1, which is present in terminals of spiking neurons (Brandstätter et al., 1996; Morgans et al., 1996). The concentration of syntaxin 1 was shown to be critical for $\mathrm{Ca}^{2+}$ cooperativity of transmitter release (Stewart et al., 2000).

\section{Potential significance of linear synaptic transfer between fly tangential cells}

V1 gets input from at least three VS neurons with partly overlapping receptive fields. During visual stimulation in vivo, it is not possible to separate the influences of these synapses. Therefore, it cannot be excluded that each of the synapses operates nonlinearly, with individual nonlinearities compensating each other. However, the relationship between $\Delta E_{\text {pre }}$ and $\Delta\left[\mathrm{Ca}^{2+}\right]_{\text {pre }}$ is linear, regardless of the extent of linearity of synaptic transfer from individual VS neurons to V1. Therefore, the overall linear synaptic transmission is best explained by a linear transfer characteristic of each of the synapses. Unequivocal evidence for linearity of individual synapses requires selective stimulation of single VS neurons. Because the receptive fields of the VS neurons overlap to a large extent, visual stimulation of only a single VS cell is more or less impossible. Therefore, artificial stimulation by current injection would be necessary. Alternatively, single neurons may be "knocked out" by clamping their membrane potential, by laser ablation after filling with a fluorescent dye, or by application of intracellularly acting $\mathrm{Ca}^{2+}$ channel blockers or $\mathrm{Ca}^{2+}$ buffers (Selverston and Miller, 1980; Warzecha et al., 1993;
Borst and Sakmann, 1996; Kovalchuk et al., 2000). Any of these techniques could help to assess the role of single VS neurons in the VS-V1 network.

The above experiments should provide new insights into the mechanisms underlying synaptic transmission. However, what is functionally relevant is the overall transfer characteristic of the whole network. In the context of optomotor gaze stabilization, the exact comparison of motion signals from both visual hemispheres may be enhanced if motion information transfer from one side of the brain to the other, as mediated by the V1 neuron, acts as linearly as possible. If not, a mismatch between unilateral and heterolateral tangential neurons might arise with respect to their stimulus dependence.

In the present work, we used sensory stimulation instead of artificial excitation to characterize VS-V1 synapses in vivo. There is still one important difference between the stimuli in our experiments and the stimuli the animal encounters in nature: the strength of real life stimuli varies permanently with a complex time course. In a forthcoming study, we will therefore characterize transfer of visual motion information at VS-V1 synapses during dynamic stimulation (our unpublished observations).

\section{REFERENCES}

Augustine GJ, Charlton MP, Smith SJ (1985) Calcium entry into voltage-clamped presynaptic terminals of squid. J Physiol (Lond) 367:143-162.

Beutner D, Voets T, Neher E, Moser T (2001) Calcium dependence of exocytosis and endocytosis at the cochlear inner hair cell afferent synapse. Neuron 29:681-690.

Bollmann JH, Sakmann B, Borst JGG (2000) Calcium sensitivity of glutamate release in a calyx-type terminal. Science 289:953-957.

Borst JGG, Sakmann B (1996) Calcium influx and transmitter release in a fast CNS synapse. Nature 383:431-434.

Borst JGG, Sakmann B (1998). Calcium current during a single action potential in a large presynaptic terminal of the rat brainstem. J Physiol (Lond) 506:143-157.

Brandstätter JH, Wässle H, Betz H, Morgans CW (1996) The plasma membrane protein SNAP-25, but not syntaxin, is present at photoreceptor and bipolar cell synapses in the rat retina. Eur $\mathrm{J}$ Neurosci 8:823-828.

Corey DP, Dubinsky JM, Schwartz EA (1984) The calcium current in inner segments of rods from the salamander (Ambystoma tigrinum) retina. J Physiol (Lond) 354:557-575.

Cox CL, Denk W, Tank DW, Svoboda K (2000) Action potentials reliably invade axonal arbors of rat neocortical neurons. Proc Natl Acad Sci USA 97:9724-9728. 
Dodge FA, Rahamimoff R (1967) Co-operative action of calcium ions in transmitter release at the neuromuscular junction. J Physiol (Lond) 193:419-432.

Dürr V, Egelhaaf M (1999) In vivo calcium accumulation in presynaptic and postsynaptic dendrites of visual interneurons. J Neurophysiol 82:3327-3338.

Egelhaaf M, Borst A (1993) A look into the cockpit of the fly: visual orientation, algorithms, and identified neurons. $\mathrm{J}$ Neurosci 13:4563-4574.

Egelhaaf M, Borst A (1995) Calcium accumulation in visual interneurons of the fly: stimulus dependence and relationship to membrane potential. J Neurophysiol 73:2540-2552.

Gleason E, Borges S, Wilson M (1994) Control of transmitter release from retinal amacrine cells by $\mathrm{Ca}^{2+}$ influx and efflux. Neuron 13:1109-1117.

Haag J, Borst A (2000) Spatial distribution and characteristics of voltage-gated calcium signals within visual interneurons. J Neurophysiol 83:1039-1051.

Haag J, Egelhaaf M, Borst A (1992) Dendritic integration of motion information in visual interneurons of the blowfly. Neurosci Lett 140:173-176.

Hausen K (1984) The lobula-complex of the fly: structure, function and significance in visual behaviour. In: Photoreception and vision in invertebrates (Ali MA, ed), pp 523-555. New York: Plenum.

Hausen K, Egelhaaf M (1989) Neural mechanisms of visual course control in insects. In: Facets of vision (Stavenga DG, Hardie RC, eds), pp 391-424. Berlin: Springer.

Hausen K, Wolberg-Buchholz K, Ribi WA (1980) The synaptic organization of visual interneurons in the lobula complex of flies. A Light and electron microscopical study using silver-intensified cobaltimpregnations. Cell Tissue Res 208:371-387.

Heidelberger R, Heinemann C, Neher E, Matthews G (1994) Calcium dependence of the rate of exocytosis in a synaptic terminal. Nature 371:513-515.

Helmchen F, Imoto K, Sakmann B (1996) $\mathrm{Ca}^{2+}$ buffering and action potential-evoked $\mathrm{Ca}^{2+}$ signalling in dendrites of pyramidal neurons. Biophys J 70:1069-1081.

Helmchen F, Borst JGG, Sakmann B (1997) Calcium dynamics associated with a single action potential in a CNS presynaptic terminal. Biophys J 72:1458-1471.

Hengstenberg R (1982) Common visual response properties of giant vertical cells in the lobula plate of the blowfly Calliphora. J Comp Physiol [A] 149:179-193.

Hengstenberg R, Hausen K, Hengstenberg B (1982) The number and structure of giant vertical cells (VS) in the lobula plate of the blowfly Calliphora erythrocephala. J Comp Physiol [A] 149:163-177.

Ivanov AI, Calabrese RL (2000) Intracellular $\mathrm{Ca}^{2+}$ dynamics during spontaneous and evoked activity of leech heart interneurons: lowthreshold $\mathrm{Ca}$ currents and graded synaptic transmission. J Neurosci 20:4930-4943.

Juusola M, French AS, Uusitalo RO, Weckström M (1996) Information processing by graded-potential transmission through tonically active synapses. Trends Neurosci 19:292-297.

Kovalchuk Y, Eilers J, Lisman J, Konnerth A (2000) NMDA receptormediated subthreshold $\mathrm{Ca}^{2+}$ signals in spines of hippocampal neurons. J Neurosci 20:1791-1799.

Krapp HG, Hengstenberg B, Hengstenberg R (1998) Dendritic structure and receptive-field organization of optic flow processing interneurons in the fly. J Neurophysiol 79:1902-1917.

Krapp HG, Hengstenberg R, Egelhaaf M (2001) Binocular contributions to optic flow processing in the fly visual system. J Neurophysiol 85:724-734

Morgans CW, Brandstätter JH, Kellerman J, Betz H, Wässle H (1996) A SNARE complex containing syntaxin 3 is present in ribbon synapses of the retina. J Neurosci 16:6713-6721.

Mori K, Nagao H, Yoshihara Y (1999) The olfactory bulb: coding and processing of odor molecule information. Science 286:711-715.

Oertner TG, Brotz TM, Borst A (2001) Mechanisms of dendritic calcium signaling in fly neurons. J Neurophysiol 85:439-447.

Peng Y, Zucker RS (1993) Release of LHRH is linearly related to the time integral of presynaptic $\mathrm{Ca}^{2+}$ elevation above a threshold level in bullfrog sympathetic ganglia. Neuron 10:465-473.

Regehr WG, Atluri PP (1995) Calcium transients in cerebellar granule cell presynaptic terminals. Biophys J 68:2156-2170.

Sabatini BL, Regehr WG (1996) Timing of neurotransmission at fast synapses in the mammalian brain. Nature 384:170-172.

Sabatini BL, Regehr WG (1998) Optical measurement of presynaptic calcium currents. Biophys J 74:1549-1563.

Sala F, Hernandez-Cruz A (1990) Calcium diffusion modeling in a spherical neuron. Relevance of buffering properties. Biophys $\mathrm{J}$ 57:313-324.

Schneggenburger R, Neher E (2000) Intracellular calcium dependence of transmitter release rates at a fast central synapse. Nature 406:889-893.

Selverston AI, Miller JP (1980) Mechanisms underlying pattern generation in lobster stomatogastric ganglion as determined by selective inactivation of identified neurons. I. Pyloric system. J Neurophysiol 44:1102-1121.

Sinha RS, Wu LG, Saggau P (1997) Presynaptic calcium dynamics and transmitter release evoked by single action potentials at mammalian central synapses. Biophys J 72:637-651.

Smith SJ, Augustine GJ, Charlton MP (1985) Transmission at voltageclamped giant synapse of the squid: evidence for cooperativity of presynaptic calcium action. Proc Natl Acad Sci USA 82:622-625.

Stewart BA, Mohtashami M, Trimble WS, Boulianne GL (2000) SNARE proteins contribute to calcium cooperativity of synaptic transmission. Proc Natl Acad Sci USA 97:13955-13960.

Takahashi A, Camacho P, Lechleiter JD, Herman B (1999) Measurement of intracellular calcium. Physiol Rev 79:1089-1125.

von Gersdorff H (2001) Synaptic ribbons: versatile signal transducers. Neuron 29:7-10.

Vranesic I, Knöpfel T (1991) Calculation of calcium dynamics from single wavelength fura-2 fluorescence recordings. Pflügers Arch 418:184-189.

Warzecha AK, Egelhaaf M, Borst A (1993) Neural circuit tuning fly visual interneurons to motion of small objects. I. Dissection of the circuit by pharmacological and photoinactivation techniques. J Neurophysiol 69:329-339.

Warzecha AK, Kretzberg J, Egelhaaf M (2000) Reliability of a fly motion-sensitive neuron depends on stimulus parameters. J Neurosci 20:8886-8896.

Witkovsky P, Schmitz Y, Akopian A, Krizaj D, Tranchina D (1997) Gain of rod to horizontal cell synaptic transfer: relation to glutamate release and a dihydropyridin-sensitive calcium current. J Neurosci 17:7297-7306.

Wu LG, Saggau P (1994) Presynaptic calcium is increased during normal synaptic transmission and paired-pulse facilitation, but not in long-term potentiation in area CA1 of hippocampus. J Neurosci 14:645-654.

Zucker RS, Fogelson AL (1986) Relationship between transmitter release and presynaptic calcium influx when calcium enters through discrete channels. Proc Natl Acad Sci USA 83:3032-3036. 